\title{
Determinants of modern contraceptive use among sexually active men in Ethiopia; using EDHS 2016 national survey
}

Tamrat Shaweno ${ }^{1 *}$ and Zerihun Kura ${ }^{2}$

\begin{abstract}
Background: Recently, the focus of family planning programs has changed from female oriented to men oriented, or both partner oriented to have effective outcomes. Although, contraceptive use among sexually active women was exhaustively researched; there is still a huge gap on modern contraceptive use and its determinants among sexually active men in Ethiopia.
\end{abstract}

Objectives: We assessed the determinants of contraceptive use among sexually active men in Ethiopia using national survey data.

Method: The data source for this study was the 2016's Ethiopian Demographic and Health Survey of men aged above 15-59 years. We analyzed data of 12, 688 sexually active men in the past 12 months prior to the survey using STATA version 14.1. Bivariate and multivariable multinomial logistic regression analysis was conducted and statistical significance was set at $p$ value $<0.05$.

Result: From a total of 12, 688 sexually active men in Ethiopia, 9378 (73.9\%) didn't use any modern contraception or use traditional methods, 2394 (18.9\%) use partner methods for those who reported using a method through their partner (such as pill, IUD, injections, female sterilization and Norplant) and the rest 916 (7.2\%) used male methods for those who reported using male only methods (such as condoms and male sterilization). In the adjusted multinomial logistic regression model, men's age categories 25-34 years (AOR:2.0; 95\% Cl=1.5-2.5), 35-44 (AOR: 2.8; 95\% $\mathrm{Cl}=(2.0-3.8)$, and $45^{+}$years (AOR: 1.5; $95 \% \mathrm{Cl}=1.0-2.6)$, being rural resident (AOR: 1.60; (95\%Cl=1.3-2.2), married and living with partner (AOR: $0.03 ;(95 \% \mathrm{Cl}=0.01-$ 0.06), who attended secondary (AOR:1.2; $(95 \% \mathrm{Cl}=0.8-1.9)$ and higher (AOR: $1.4 ;(95 \% \mathrm{Cl}=1.2-2.5)$ education, whose partner was working (AOR: 1.6; $(95 \% \mathrm{Cl}=1.3-2.2)$, having three and above children (AOR: 0.5; $(95 \% \mathrm{Cl}=0.3-0.8)$, reading newspaper/ magazines at least once a week or less than once a week, listening to radio at least once a week, watching television at least once a week and watching television less than once a week were significantly associated with use of male method than traditional/no method as compared to their respective references.

Conclusion: Modern contraceptive use among sexually active men in Ethiopia is low and multiple factors determined it. Close monitoring and supporting of sexually active men with age above 25 years, rural background, higher educational level, whose partner was working, having three and more children and little exposure to media may increase men's use of modern contraceptives.

Keywords: Modern contraceptive, Male method, EDHS 2016, Ethiopia

\footnotetext{
* Correspondence: babiynos@gmail.com

'Department of Epidemiology, Faculty of Public Health, Jimma University, Jimma, Ethiopia

Full list of author information is available at the end of the article
}

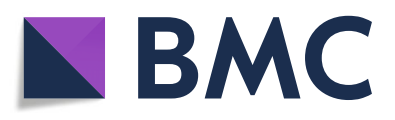

(- The Author(s). 2020 Open Access This article is licensed under a Creative Commons Attribution 4.0 International License, which permits use, sharing, adaptation, distribution and reproduction in any medium or format, as long as you give appropriate credit to the original author(s) and the source, provide a link to the Creative Commons licence, and indicate if changes were made. The images or other third party material in this article are included in the article's Creative Commons licence, unless indicated otherwise in a credit line to the material. If material is not included in the article's Creative Commons licence and your intended use is not permitted by statutory regulation or exceeds the permitted use, you will need to obtain permission directly from the copyright holder. To view a copy of this licence, visit http://creativecommons.org/licenses/by/4.0/. The Creative Commons Public Domain Dedication waiver (http://creativecommons.org/publicdomain/zero/1.0/) applies to the data made available in this article, unless otherwise stated in a credit line to the data. 


\section{Introduction}

The importance of modern contraceptive use is now well recognized, not only to improve women and child health, but also to contribute to related issues such as gender equality, better child health, an improved response to HIV, greater education outcomes and poverty reduction [1]. To reaffirm the promise of universal access to reproductive health and family planning, the international community is giving special attention to regions and countries lagging behind [1-3]. Huge gaps exist in demand for family planning satisfied with modern contraceptives in countries where overall contraceptive use is low or where many sexually active groups rely on traditional methods of contraception [2, 3]. At the end of 2015, less than half of total demand for contraceptives was being met with modern methods in 54 countries (of which more than $60 \%$ are in Africa) [4]. Between 2015 and 2030, the time period of the 2030 Agenda for Sustainable Development, contraceptive use is projected to increase particularly in countries where less than half of reproductive age groups currently use contraception [4]. In line with this vision, Ethiopia has committed to increase the modern contraceptive prevalence rate from 35\% to 55\% amongst married women by 2020 and reducing the total fertility rate from 4.6 to 3.0 [5]. Family planning programs have traditionally focused primarily on women; men being over looked and given lesser attention [6]. Although, some studies have highlighted the influence of men on reproductive decisions such as contraceptive use, still information is scarce with regard to contraceptive use among sexually active men $[6,7]$. Men, particularly in malecontrolled contexts, play a great role in influencing fertility choices [8]. However, male involvement in family planning remains limited $[9,10]$. In addition, research examining determinants of couples' modern contraceptive use has ignored men's crucial role $[11,12]$, which has eventually resulted in underlining the idea of contraceptive use as women's concern, leaving little or no role for men [13-15]. It was observed [16] that men, particularly in low socio economic settings, prefer large numbers of children both as a source of labor and profitable gain, and as a source of respect. Men's role as central decision makers, are believed to determine men's and couples' use of contraceptives [17, 18]. A men's agreement of the use of contraception is a key for effective family planning programs $[19,20]$. A study illustrated that men had complete decision making supremacy and the ability to result in compliance or submission from their partners [16].

Even though, different family planning programs excluded the participation of men [20,21], in recent years, efforts are ongoing to extend men's participation in reproductive health and use of contraceptives [22]. Findings indicated that discussion of family planning with a health worker, region, education, wealth index, number of surviving children and fertility preference were most significantly associated with modern contraceptive use among men [23, 24]. Studies from different parts of Ethiopia indicated that, over $90 \%$ of men supported and approved of using family planning; however, $36 \%$ of men didn't know about male contraceptive methods [25, 26]. But, to advocate including men in contraceptive programs, information is still scarce on determinants of modern contraceptive use among men in Ethiopia [23, 24]. Moreover, the variations of modern contraceptive use among sexually active men in Ethiopia by different variables including socio-economic characteristics, interaction with health system and access to media, and behavioral and attitudinal factors remains limited. We hypothesized that, socio-demographic factors, interaction with health system, access to media and behavioral/attitudinal factors influence modern contraceptive use among sexually active men in Ethiopia. A better understanding of determinants of modern contraceptive use among sexually active men in Ethiopia could be helpful to develop intervention strategies relevant to Ethiopia. Therefore, this study aimed to explore determinant factors that influence modern contraceptive use among sexually active men in Ethiopia using 2016 EDHS national survey data.

\section{Methods}

\section{Study design and data set}

The data set used for this study was obtained from 2016 Ethiopian Demographic Health Surveys conducted from January 18, 2016 to June 27, 2016, across the country. The survey was a population-based cross-sectional study and it is available from the MEASURE DHS database at https://dhsprogram.com/data/available-datasets.cfm. For the surveys, there were two stages. In the first stage, the total of 645 clusters (202 in urban and 443 in rural) were randomly selected proportional to the household size from the sampling strata and in the second stage, 28 households per cluster were selected using systematic random sampling. The sample allocations were derived with information obtained from the 2011 EDHS. From a total of 16,533 men, 14, 176 were eligible for an interview. A total of 12,688 eligible men were interviewed yielding a response rate of $89.5 \%$ [27]. Data were weighted to adjust for differences in probability of selection and to adjust for non-response. Our analysis was restricted to the 12, 688 (weighted) men who reported being sexually active in the 12 months prior to the survey and we excluded men who reported that either them or their partners were infecund.

\section{Study variables}

The outcome variable for this study was modern contraceptive use. We categorized modern contraceptive use into three outcome categories. These included: 
'traditional/no method' for those who reported current use of traditional or natural methods (like periodic abstinence, lactational amenorrhea and use of withdrawal method) or not using modern contraceptive methods which are ineffective in pregnancy prevention; 'partner method' for those who reported use of a method by their partner (like injections, pills, IUD, norplant, female sterilization and); and 'male method', for those who reported using male only methods (like male sterilization and condom use). The explanatory variables were grouped into five categories to see their influence on modern contraceptive use. These included socio-demographic variables (age, residence, number of children and marital status), socio-economic factors (wealth index, education and current working status of the partner), interaction with health system (discussed family planning with health worker), access to media (frequency of reading newspaper/magazine, frequency of listening to radio, frequency of watching TV) and behavioral/attitudinal factors (belief that women who use contraceptive become promiscuous and belief that contraception is a women's business).

\section{Statistical analysis}

Bivariate analyses were done to assess the association between predictor variables and outcome variable of the study using $\mathrm{X}^{2}$ tests. We selected multinomial logistic regression because it is the most suitable for the study of the outcome with three categories. Four multinomial regression models were fitted in this study. In model I we included socio demographic and partners' working status while controlling for other covariates. Model II included socio-demographic variables, partners' working status and total children ever born while controlling for the wealth index variables and variables related to media. Model III included socio demographic variables, partners' working status, total number of children ever born and wealth index while controlling for access to media. In the final model all explanatory variables were included into the model. All analyses were weighted to account for differences in sampling probabilities. Those predictor variables significantly associated with outcome variable were included in the multivariable logistic regression model in which the odds ratio with 95\% confidence intervals was estimated to identify the predictors of modern contraceptive use (male method) in Ethiopia. A $p$-value less than 0.05 were employed to declare the statistical significance.

\section{Result}

\section{Characteristics of the study participants}

From a total of 12, 688 sexually active men in Ethiopia, 9378 (73.9\%) didn't use any contraception or use traditional methods, 2394 (18.9\%) use partner methods and the rest $916(7.2 \%)$ did use male methods.
Approximately, more than one third (35\%) of the sexually active men were in the age group 15-24 years and more than two third (69.5\%) were from the rural community. Wirth regard to marital status, more than half $(56.8 \%)$ of men were married and living in marital union. Only few 1607 (12.7\%) of the respondents achieved higher education whereas, majority of the respondents attended primary education. Slightly, four men out of five $(83.5 \%)$ were currently working and majority have no child at the time of the survey (46.3\%). With regard to interaction with the health system, exactly three fourth of the respondents didn't discuss about contraception with the health care provider. Only, about 33.9\% were categorized as richest in economic class whereas, the rest $15.2,13.7,14.3$ and $22.9 \%$ were richer, middle, poorer and poorest, respectively. With regard to behavioral factors, more than four-fifth disagree that women who use contraceptive become promiscuous and contraception is a women's business [Table 1].

\section{Prevalence of modern contraceptive use among sexually active men}

The prevalence of modern contraceptive use in relation to selected socio-demographic characteristics, behavioral factors and access to media was illustrated in Table 2 . Concerning the socio-economic characteristics, a significant positive association was observed between age and use of contraceptive partner method. Sexually active men aged between 25 and 34 years (COR:1.6; 95\%CI = $1.4-1.9), \quad P<0.001)), \quad 35-44$ years $\quad($ COR:0.7; $95 \% \mathrm{CI}=$ (0.6-0.9), $P<0.001)$ ), and aged above 45 years (COR:0.3; $95 \% \mathrm{CI}=(0.2-0.4), p<0.001))$, were more likely to use a partner method compared to none /traditional method users, respectively. On the contrary, men above 35 years (COR:5.9; 95\%CI $=5.1-6.8), P<0.001)$ ), were less likely to use a male method than traditional or no method, compared to those men in the age group 15-24 years. Men with urban residence were more likely to use both a partner method $(\mathrm{COR}: 1.5 ; 95 \% \mathrm{CI}=(1.3-1.6), \quad P=$ 0.007)), and male method (COR:7.5; $95 \% \mathrm{CI}=(6.4-8.7)$, $P<0.001)$ ) compared to those men with rural residence. Married men either living (COR:7.8; 95\% CI $=(6 .-9.0)$, $P<0.001)$ ) or not living with the partner (COR:7.8; $95 \% \mathrm{CI}=(5.9-10.3), P<0.001))$ were more than seven times to report use of a partner method and married men living with the partner (COR:0.1; 95\%CI $=(0.08-$ 0.12), $P<0.001)$ ) were less likely to use a male method compared to traditional method users or non-users. Men with primary (COR:3.8; $95 \% \mathrm{CI}=(2.8-5.3), \quad P<$ $0.001)$ ), secondary (COR:11.7; 95\%CI $=(8.5-16.2), P<$ $0.001)$ ), and; higher and above (COR: $23.2 ; 95 \% \mathrm{CI}=$ (16.8-32.0), $P<0.001)$ ) educational status were more likely to use male method than traditional method or non-use of any method compared to those with no 
Table 1 Sample characteristics of sexually active men 15-59 years in Ethiopia (2016 EDHS) (weighted)

\begin{tabular}{|c|c|c|c|c|c|}
\hline & \\
\hline Characteristics & Number (N) & Percent (\%) & Characteristics & Number (N) & Percent (\%) \\
\hline Contraceptive use & & & less than once a week & 2466 & $19.4 \%$ \\
\hline None/Traditional methods & 9378 & 73.9 & not at all & 8872 & $69.9 \%$ \\
\hline vPartner methods & 2394 & 18.9 & Frequency of listening to radio & & \\
\hline Male methods & 916 & 7.2 & At least once a week & 3793 & $29.9 \%$ \\
\hline Socio-demographic factors & & & less than once a week & 3046 & $24.0 \%$ \\
\hline Age & & & not at all & 5849 & $46.1 \%$ \\
\hline $45^{+}$ & 1979 & $15.6 \%$ & Frequency of watching TV & & \\
\hline $35-44$ & 2592 & $20.4 \%$ & At least once a week & 3433 & $27.1 \%$ \\
\hline $25-34$ & 3615 & $28.5 \%$ & less than once a week & 3040 & $24.0 \%$ \\
\hline $15-24$ & 4502 & $35.5 \%$ & not at all & 6215 & $49.0 \%$ \\
\hline Residence & & & Behavioral/attitudinal factors & & \\
\hline Urban & 3866 & $30.5 \%$ & Women who use contraceptive bec & ne promiscuous & \\
\hline Rural & 8822 & $69.5 \%$ & Don't know & 796 & $6.3 \%$ \\
\hline Marital status & & & Agree & 1262 & $9.9 \%$ \\
\hline Ever married but not together & 375 & $3.0 \%$ & Disagree & 10,630 & $83.8 \%$ \\
\hline Married and living with partner & 7208 & $56.8 \%$ & Number of wives/partners & & \\
\hline Never union & 5105 & $40.2 \%$ & Two and more wives & 472 & $3.7 \%$ \\
\hline Education level of respondents & & & one wife & 6736 & $53.1 \%$ \\
\hline Higher & 1607 & $12.7 \%$ & No wife & 5480 & $43.2 \%$ \\
\hline Secondary & 2233 & $17.6 \%$ & Contraception is a women's business & & \\
\hline Primary & 5331 & $42.0 \%$ & Don't know & 690 & $5.4 \%$ \\
\hline no education & 3517 & $27.7 \%$ & Agree & 1145 & $9.0 \%$ \\
\hline Current working & & & Disagree & 10,853 & $85.5 \%$ \\
\hline
\end{tabular}

Yes

No

2093

Total children over born

3 and above

1-2 children

no child

Socio-economics factors

\section{Wealth index}

Poorest

Poorer

Middle

Richer

Richest

Interaction with health system

Discussed FP with health worker

Yes

3159

9529

Access to media

Frequency of reading newspaper/magazine

At least once a week

1350
Table 1 Sample characteristics of sexually active men 15-59 years in Ethiopia (2016 EDHS) (weighted) (Continued)

Behavioral/attitudinal factors

${ }^{*} T V$ Television

registered educational status. Similarly, men with the same educational status were more likely to use partner method too, but the odds of use of male method are significantly higher compared to partner method. Men having one or two child (COR:6.6; 95\%CI $=(5.8-7.5), P<0.001)$ ); and three or more children (COR:3.5; 95\%CI $=(3.1-3.9), P<$ 0.001)) were more likely to use partner method but less likely to use a male method compared to those men with no children. Men from economic classes of richer (COR: $0.2 ; 95 \% \mathrm{CI}=(16.8-32.0), P<0.001)$ ), middle (COR: 0.1; $95 \% \mathrm{CI}=(0.1-0.2), P<0.001)$, poorer $(\mathrm{COR}: 0.1 ; 95 \% \mathrm{CI}=$ $(0.1-0.2), P<0.001)$, and poorest $(\mathrm{COR}: 0.1 ; 95 \% \mathrm{CI}=$ (0.1-0.2), $P<0.001$ ) were less likely to use male method as compared richest men. Men who discussed FP (family planning) with health worker (COR: $2.4 ; 95 \% \mathrm{CI}=(2.2-$ 2.7), $P<0.001$ ) were more than two times to use a partner method compared to use traditional methods/no methods. Conversely, these men were less likely to use a male method than traditional or no use of any method compared to those who didn't discuss about FP with health worker (COR: $0.8 ; 95 \% \mathrm{CI}=(0.7-1.0), P<0.001)$. Men who agreed that, women who use contraceptive becomes 
Table 2 Bivariate association between modern contraceptive use and various background characteristics, EDHS 2016, Ethiopia (weighted)

\begin{tabular}{|c|c|c|c|c|c|c|}
\hline \multirow{2}{*}{$\begin{array}{l}\text { Characteristics } \\
\text { Age respondents }\end{array}$} & \multicolumn{3}{|c|}{ Partner method vs. none/traditional method } & \multicolumn{3}{|c|}{ Male method vs. none/traditional method } \\
\hline & COR & $P$-value & $\% \mathrm{Cl}$ & COR & $P$-value & $\% \mathrm{Cl}$ \\
\hline $45^{+}$ & 3.7 & 0.001 & $3.2-4.4$ & 0.3 & 0.001 & $0.2-0.4$ \\
\hline $35-44$ & 5.9 & 0.001 & $5.1-6.8$ & 0.7 & 0.001 & $0.6-0.9$ \\
\hline $25-34$ & 5.3 & 0.001 & $4.6-, 6.1$ & 1.6 & 0.001 & $1.4-1.9$ \\
\hline $15-24$ & $0^{\mathrm{b}}$ & & & $0^{\mathrm{b}}$ & & \\
\hline
\end{tabular}

Residence

\begin{tabular}{|c|c|c|c|c|c|c|}
\hline Urban & 1.5 & 0.077 & $1.3-1.6$ & 7.5 & 0.001 & $6.4-8.7$ \\
\hline Rural & $0^{b}$ & & & $0^{\mathrm{b}}$ & & \\
\hline
\end{tabular}

\section{Marital status}

Ever married but not together 7.8

Never union

\section{Education of respondents}

Higher and above
Secondary
Primary
None

\section{0}

1.0

1.0

$0^{\mathrm{b}}$

\section{Current working}

Yes

6.0

No

$0^{b}$

Total children over born

3 and above
$1-2$ children
No child

\section{5}

6.6

$0^{b}$

0.001
0.639
0.824

0.001

$4.8-7.4$

$1.7-2.3$

$0.9-1.2$

$0.9-1.1$

Socio-economics factors

\section{Wealth index}

Poorest
Poorer
Middle
Richer
Richest

$\begin{array}{ll}0.3 & 0.001 \\ 0.7 & 0.001 \\ 0.9 & 0.164 \\ 1.0 & 0.687 \\ 0^{b} & \end{array}$

0.001

$3.1-3.9$

0.001

$5.8-7.5$

$0^{\mathrm{b}}$

Interaction with health system

Discussed FP with health worker

Yes

2.4
$0^{b}$

0.001

$2.2-2.7$

$0.2-0.6$

$0.6,0.8$

$0.8-1.0$

$0.9-1.1$

23.2

0.001

0.001

0.001

3.8

$0^{b}$

1.7

(1)

0.007

$1.1-1.5$

$0^{b}$

\section{Access to media}

Frequency of reading newspaper/magazine

$\begin{array}{ll}\text { At least once a week } & 2.0 \\ \text { Less than once a week } & 1.634 \\ \text { Not at all } & 0^{\mathrm{b}}\end{array}$

\section{Frequency of listening to radio}

At least once a week

Less than once a week
$1.7-2.3$

$1.5-1.8$

0.001

0.001

1

(1)

0.001
0.001

0.001

$\begin{array}{llllll}2.0 & 0.001 & 1.8-2.3 & 4.7 & 0.001 & 4.0-5.6 \\ 1.323 & 0.001 & 1.2-1.5 & 2.5 & 0.001 & 2.1-3.1\end{array}$

\begin{tabular}{|c|c|c|c|}
\hline (2020) 5:5 & & & Page 5 \\
\hline traditional method & Male & s. none/tr & method \\
\hline$\% \mathrm{Cl}$ & COR & $P$-value & $\% \mathrm{Cl}$ \\
\hline $3.2-4.4$ & 0.3 & 0.001 & $0.2-0.4$ \\
\hline $5.1-6.8$ & 0.7 & 0.001 & $0.6-0.9$ \\
\hline 4.6-, 6.1 & 1.6 & 0.001 & $1.4-1.9$ \\
\hline & $0^{\mathrm{b}}$ & & \\
\hline $1.3-1.6$ & 7.5 & 0.001 & $6.4-8.7$ \\
\hline & $0^{\mathrm{b}}$ & & \\
\hline 5.9-10.3 & 1.7 & 0.001 & $1.3-2.3$ \\
\hline $6.7-8.9$ & 0.1 & 0.001 & $0.1-0.2$ \\
\hline & $0^{\mathrm{b}}$ & & \\
\hline $1.7-2.3$ & 23.2 & 0.001 & $6.9-32.0$ \\
\hline $0.9-1.2$ & 11.7 & 0.001 & $8.5-16.2$ \\
\hline $0.9-1.1$ & 3.8 & 0.001 & $2.8-5.3$ \\
\hline & $0^{\mathrm{b}}$ & & \\
\hline $4.8-7.4$ & 1.3 & 0.007 & $1.1-1.5$ \\
\hline & $0^{\mathrm{b}}$ & & \\
\hline $3.1-3.9$ & 0.1 & 0.099 & $0.1,0.2$ \\
\hline $5.8-7.5$ & 0.5 & 0.595 & $0.4-0.5$ \\
\hline & $0^{\mathrm{b}}$ & & \\
\hline $0.2-0.6$ & 0.1 & 0.001 & $0.1-0.2$ \\
\hline $0.6,0.8$ & 0.1 & 0.001 & $0.1-0.2$ \\
\hline $0.8-1.0$ & 0.1 & 0.001 & $0.1-0.2$ \\
\hline $0.9-1.1$ & 0.2 & 0.001 & $0.2-0.3$ \\
\hline & $0^{\mathrm{b}}$ & & \\
\hline $2.2-2.7$ & 0.8 & 0.031 & $0.7-1.0$ \\
\hline & $0^{\mathrm{b}}$ & & \\
\hline $1.7-2.3$ & 5.1 & 0.001 & $4.3-6.2$ \\
\hline $1.5-1.8$ & 3.7 & 0.001 & $3.2-4.4$ \\
\hline
\end{tabular}


Table 2 Bivariate association between modern contraceptive use and various background characteristics, EDHS 2016, Ethiopia (weighted) (Continued)

\begin{tabular}{|c|c|c|c|c|c|c|}
\hline \multirow{2}{*}{$\begin{array}{l}\text { Characteristics } \\
\text { Age respondents }\end{array}$} & \multicolumn{3}{|c|}{ Partner method vs. none/traditional method } & \multicolumn{3}{|c|}{ Male method vs. none/traditional method } \\
\hline & $\mathrm{COR}$ & $P$-value & $\% \mathrm{Cl}$ & $\mathrm{COR}$ & $P$-value & $\% \mathrm{Cl}$ \\
\hline Not at all & $0^{\mathrm{b}}$ & & & $0^{\mathrm{b}}$ & & \\
\hline \multicolumn{7}{|l|}{ Frequency of watching TV } \\
\hline At least once a week & 2.2 & 0.001 & $2.0-2.5$ & 9.7 & 0.001 & $2.5-11.8$ \\
\hline Less than once a week & 1.9 & 0.001 & $1.7-2.1$ & 3.6 & 0.001 & $2.1,4.6$ \\
\hline Not at all & $0^{\mathrm{b}}$ & & & $0^{\mathrm{b}}$ & & \\
\hline \multicolumn{7}{|c|}{ Behavioral/attitudinal factors } \\
\hline \multicolumn{7}{|c|}{ Women who use contraceptive become promiscuous } \\
\hline Don't know & 0.2 & 0.001 & $0.1-0.3$ & 0.1 & 0.001 & $0.1-0.2$ \\
\hline Agree & 0.8 & 0.002 & $0.7-0.9$ & 0.7 & 0.016 & $0.6-0.9$ \\
\hline Disagree & $0^{\mathrm{b}}$ & & & $0^{\mathrm{b}}$ & & \\
\hline \multicolumn{7}{|l|}{ Number of wives/partners } \\
\hline Two and more wives & 3.2 & 0.001 & $2.5-4.1$ & 0.2 & 0.001 & $0.01-0.13$ \\
\hline One wife & 6.0 & 0.001 & $5.3-6.8$ & 0.1 & 0.001 & $0.1-0.2$ \\
\hline No wife & $0^{\mathrm{b}}$ & & & $0^{\mathrm{b}}$ & & \\
\hline \multicolumn{7}{|c|}{ Contraception is a women's business } \\
\hline Don't know & 0.1 & 0.001 & $0.1-0.2$ & 0.2 & 0.001 & $0.1-0.3$ \\
\hline Agree & 0.8 & 0.010 & $0.7-1.0$ & 0.5 & 0.001 & $0.4-0.7$ \\
\hline Disagree & $0^{b}$ & & & $0^{\mathrm{b}}$ & & \\
\hline
\end{tabular}

${ }^{*} \mathrm{COR}$ adjusted odds ratio, $\mathrm{Cl}$ confidence interval, $\mathrm{O}^{b}$ reference category, $F P$ family planning $T V$ television

promiscuous were less likely to use a partner method (COR: $0.8 ; 95 \% \mathrm{CI}=(0.7-0.9)), \quad P<0.002)$ or a male method (COR: $0.7 ; 95 \% \mathrm{CI}=(0.6-0.9), P<0.016)$ than use of traditional method /no method as compared to men who disagreed to the thought that, women who use contraceptive become promiscuous. (For details see Table 2).

\section{Determinants of modern contraceptive use among sexually active men}

In the adjusted multinomial logistic regression model, age of men, residence, marital status, partners working, number of ever born children, access to media, frequency of listening to radio and frequency of watching TV were significantly associated with use of male method than partner method compared to use of traditional method / no method. Men aged above 25 years were less likely to report use of partner method than use of traditional /no method compared to men whose age 15-24 years. Contrariwise, these men were less likely to use partner method than use of traditional/no method compared to men aged 15-24 years. Men aged 25-34 years (AOR: $2.0 ; 95 \% \mathrm{CI}=(1.5-2.5), 35-44$ years $(\mathrm{AOR}$ : 2.8; $95 \% \mathrm{CI}=(2.0-3.8)$ ), and $45^{+}$years $(\mathrm{AOR}$ : 1.5; $95 \% \mathrm{CI}=(1.0-2.6))$ were approximately, $2.0(p=0.004)$, $3.0(p<0.01)$ and 1.5 times $(p<0.01)$ more likely to use male methods than traditional /no method respectively, compared to men aged 15-24 years. Men with urban residence were nearly two times more likely to use male method than traditional/no methods compared to men from rural residence (AOR: 1.60; $(95 \% \mathrm{CI}=1.3-2.2),(p<$ $0.001)$ ). Men who were ever married and living with the partner were 0.03 times, $(p<0.001)$ less likely to use male method than traditional/no method compared to men not in marital union (AOR: 0.03; $(95 \% \mathrm{CI}=0.01-0.06)), \quad(p<0.001)) . \quad$ Men whose educational status was secondary (AOR: 1.2; $(95 \% \mathrm{CI}=0.8-1.9),(p<0.024))$ and higher (AOR: 1.4; $(95 \% \mathrm{CI}=1.2-2.5),(p<0.001))$ were significantly associated with use of male method than traditional /no method compared to men who didn't attend formal education. There were no significant associations observed among partner method users of similar educational category. Men whose partners' work was significantly associated with use of male method (AOR: 1.6; $(95 \% \mathrm{CI}=1.3-2.2), \quad(p<0.001)) \quad$ than traditional /no method as compared to men whose partners were not working. Having one or two child was not significantly associated with use male method (AOR: 1.2; $(95 \% \mathrm{CI}=0.8-1.8), \quad(p>0.050)) \quad$ than traditional/no method as compared to men having no children. Men having more than three and above children were 0.5 times less likely to use male method than traditional/ no method as compared to men having no children (AOR: 0.5; $(95 \% \mathrm{CI}=0.3-0.8),(p<0.001)$ ). 
With regard to access to media, men reading newspaper /magazine at least once a week (AOR: 1.4; $(95 \% \mathrm{CI}=1.1-1.7),(p<0.001))$ and below once a week (AOR: $1.5 ; \quad(95 \% \mathrm{CI}=1.2-1.8), \quad(p<0.001))$ were more than 1.5 times more likely to use male method than traditional methods as compared to men not reading newspaper /magazine at all. Similarly, men listening to radio at least once a week were more likely to use male method (AOR: 1.5; $(95 \% \mathrm{CI}=1.2-1.9),(p<0.002))$ than traditional /no method as compared to men not listening to radio at all. Men watching TV at least once a week (AOR: $1.9 ; \quad(95 \% \mathrm{CI}=1.5-2.4), \quad(p<0.001))$ and below once a week (AOR: 1.5; $(95 \% \mathrm{CI}=1.1-1.9),(p<0.003))$ were approximately two times more likely to use male method than traditional /no method as compared to men not watching TV at all [Table 3].

\section{Discussion}

Currently, provision of safe, effective and affordable modern contraceptive methods is emphasized to achieve high levels of demand satisfied for family planning through addressing both women's and men's sexual and reproductive health needs [28]. This study illustrated determinants of modern contraceptive use among sexually active men in Ethiopia using EDHS 2016 national survey. In the final model a total of eight variables showed significant association with modern contraceptive use among sexually active men. In this study, age categories of 25-34 and 35-44 were more likely to use male method or partner method than traditional/no method as compared to men in the age categories of 15-24 years' age. Compared to studies from Kenya [29] and Tanzania [30] this finding is not consistent in which men aged 25 years and above were less likely to report use of a partner method than use of a traditional/no method compared to those under 25 years. Part of explanation for this variation could be the increased awareness of youth reproductive health in Ethiopia might have increased the uptake of male method too. With regard to residence; men residing in the urban part of the country were more likely to use male method than traditional/ no method as compared to men residing in rural part of Ethiopia. Compared to studies from Kenya [29], and Nigeria [31], this finding was consistent in which men from rural community were less likely to use male method than traditional /no method as compared to men from urban. But, it was inconsistent to a study [32] in which residents of rural community were more likely to use modern contraceptives. In this study, men married and living with their partner were less likely to use male method than traditional /no method as compared to men not in marital union at all. Although, we didn't find related literature on this part, our explanation for this could be men living with their partner might have full confidence and trust with their partner so that they can be negligible in use of male method. Concerning to educational status, men who attended secondary and higher education were more likely to use male method than traditional /no method as compared to men who didn't attend any education. Compared to studies from Uganda $[23,32]$, this finding is consistent in that men with secondary and above level of education were more likely to use modern contraceptives.

Men, whose partners were currently working, were more likely to use partner method or male method than traditional/no method as compared to men whose partners were not currently working. Compared to studies from other settings, this finding was consistent with the study from Nigeria [33] and in which men whose partners were currently working were more likely to utilize modern contraceptives.

In this study, men with number of ever born children equals three or more were less likely to use male method than traditional/no method compared to men without children. Compared to other studies [33], this finding was not consistent in that men with increasing number of children were more likely to use modern contraceptives. The difference can be explained from, men with large family size in Ethiopia may fear to have additional number of children due to economic and social problems, thus they might prefer to use contraceptives.

With respect to access to media, the frequency of reading newspapers/magazines, frequency of listening to radio and frequency of watching TV showed significant association with use of modern contraceptive. Men who read newspapers/magazines at least once or below once a week were more likely to use male method than traditional/no method as compared to men who didn't read newspapers/magazines at all. Similarly, men who listen to radio at least once a week were more likely to use male method than traditional/no method compared to men who didn't listen to radio at all. In the same fashion, men who watch TV at least once or less than once a week were more likely to use partner method or male method than traditional/no method as compared to men who didn't listen to radio or watch TV at all. As we compare to other findings $[29,30]$, these findings were consistent.

Unlike other studies done so far, wealth index [23, 31, 32], were not independently associated with modern contraceptive use in this study. The explanation can be from differences in study setting, sample size, study design and definitions.

\section{Conclusions}

In this study, we considered multiple factors that contributed to modern contraceptive use among sexually active men in Ethiopia. Men with advanced age and urban 
Table 3 Multivariate association between modern contraceptive use and various background characteristics, EDHS 2016, Ethiopia (weighted)

\begin{tabular}{|c|c|c|c|c|c|c|c|c|}
\hline \multirow{2}{*}{$\begin{array}{l}\text { Characteristics } \\
\text { Age respondents }\end{array}$} & \multicolumn{2}{|c|}{ Model I } & \multicolumn{2}{|c|}{ Model II } & \multicolumn{2}{|c|}{ Model III } & \multicolumn{2}{|c|}{ Model IV } \\
\hline & $\mathrm{aOR}$ & $\% \mathrm{Cl}$ & $\mathrm{aOR}$ & $\% \mathrm{Cl}$ & $\mathrm{aOR}$ & $\% \mathrm{Cl}$ & $\mathrm{aOR}$ & $\% \mathrm{Cl}$ \\
\hline $45^{+}$ & 1.9 & $1.3-3.0$ & 1.7 & $1.2-2.9$ & 1.6 & $1.1-2.8$ & 1.5 & $1.0-2.6$ \\
\hline $35-44$ & 3.2 & $2.3-4.3$ & 3.1 & $2.2-4.2$ & 3.0 & $2.2-4.1$ & 2.8 & $2.0-3.8$ \\
\hline $25-34$ & 2.3 & $1.9-2.7$ & 2.2 & $1.8-2.7$ & 2.1 & $1.7-2.6$ & 2.0 & $1.5-2.5$ \\
\hline $15-24$ & $0^{b}$ & & $0^{b}$ & & $0^{b}$ & & $0^{b}$ & \\
\hline \multicolumn{9}{|l|}{ Residence } \\
\hline Urban & 2.0 & $1.6-2.5$ & 1.9 & $1.5-2.4$ & 1.8 & $1.4-2.3$ & 1.6 & $1.3-2.2$ \\
\hline Rural & $0^{b}$ & & $0^{b}$ & & & & & \\
\hline \multicolumn{9}{|l|}{ Marital status } \\
\hline Ever married but not together & 1.2 & $0.8-1.9$ & 1.1 & $0.7-1.7$ & 1.0 & $0.7-1.8$ & 0.9 & $0.6-1.4$ \\
\hline Married and living with partner & 0.1 & $0.06-0.1$ & 0.1 & $0.05-0.09$ & 0.04 & $0.03-0.08$ & 0.03 & $0.01-0.06$ \\
\hline Never union & $0 \mathrm{~b}$ & & ob & & $0^{b}$ & & $0^{b}$ & \\
\hline \multicolumn{9}{|l|}{ Education level } \\
\hline Higher & 2.1 & $1.5-3.1$ & 1.8 & $1.4-3.0$ & 1.6 & $1.3-2.8$ & 1.4 & $1.2-2.5$ \\
\hline Secondary & 1.5 & $1.1-2.2$ & 1.4 & $1.1-2.1$ & 1.3 & $1.0-2.0$ & 1.2 & $0.8-1.9$ \\
\hline Primary & 1.3 & $0.9-1.8$ & 0.9 & $0.8-1.7$ & 0.8 & $0.7-1.6$ & 0.6 & $0.6-1.4$ \\
\hline No education & $0^{b}$ & & $0^{\mathrm{b}}$ & & $0^{\mathrm{b}}$ & & $0^{\mathrm{b}}$ & \\
\hline \multicolumn{9}{|l|}{ Partners working status } \\
\hline Yes & 2.0 & $1.6-2.5$ & 1.8 & $1.5-2.4$ & 1.7 & $1.4-2.3$ & 1.6 & $1.3-2.2$ \\
\hline No & $0 \mathrm{~b}$ & & & & & & & \\
\hline \multicolumn{9}{|l|}{ Total children ever born } \\
\hline 3 and above & & & 0.3 & $0.1-0.6$ & 0.4 & $0.2-0.7$ & 0.5 & $0.3-0.8$ \\
\hline $1-2$ children & & & 0.9 & $0.6-1.5$ & 1.1 & $0.7-1.7$ & 1.2 & $0.8-1.8$ \\
\hline No child & & & $0^{b}$ & & $0^{b}$ & & $0^{b}$ & \\
\hline \multicolumn{9}{|l|}{ Wealth index } \\
\hline Rich & & & & & 1.2 & $0.8-1.6$ & 1.3 & $0.9-1.7$ \\
\hline Medium & & & & & 0.6 & $0.4-1.1$ & 0.8 & $0.5-1.2$ \\
\hline Poor & & & & & - & & - & \\
\hline \multicolumn{9}{|l|}{ Discussed FP with health worker } \\
\hline Yes & & & & & & & 0.7 & $0.6-0.8$ \\
\hline No & & & & & & & $0^{\mathrm{b}}$ & \\
\hline
\end{tabular}

\section{Access to media}

Frequency of reading newspaper/magazine

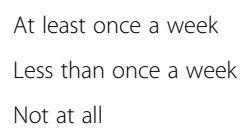

$\begin{array}{ll}1.4 & 1.1-1.7 \\ 1.5 & 1.2-1.8 \\ 0^{b} & \end{array}$

\section{Frequency of listening Radio}

\footnotetext{
At least once a week

Less than once a week

Not at all
}

$\begin{array}{ll}1.5 & 1.2-1.9 \\ 1.3 & 0.9-1.6 \\ 0^{b} & \end{array}$

Frequency of watching TV

\begin{tabular}{lr} 
At least once a week & 1.9 \\
Less than once a week & $1.5-2.4$ \\
Not at all & $1.1-1.9$ \\
\hline
\end{tabular}


residence were more likely to use modern contraceptives. In addition, men who were married and living with their spouse and men with educational level of secondary or higher were more likely to use modern contraceptives. The increasing number of ever born children was also positively associated with modern contraceptive use among sexually active men. Lastly, an exposure to sensitizing medias including newspaper, radio and TV increased the likelihood of modern contraceptive use among sexually active men in Ethiopia.

Thus, close monitoring and follow up of sexually active men with the above identified risk factors is highly recommended. Moreover, reproductive health programs aiming to increase uptake of modern contraceptives in this population of sexually active men in Ethiopia should consider the importance of men education and ensure access to media particularly, newspapers, radio and television.

\section{Abbreviations}

Cl: Confidence Interval; EDHS: Ethiopian Demographic Health Survey; AOR: Adjusted Odds Ratio; MEASURE DHS: Monitoring and Evaluation to Assess and Use Results Demographic and Health Surveys

\section{Acknowledgements}

The authors would like to acknowledge that the Ethiopian Demographic and Health Survey 2016 data used in this study were obtained from the DHS office; they have given permission to access the data, after we have prepared the proposal on the title.

\section{Ethical approval and consent to participate}

Ethical clearance for the 2016 EDHS was provided by the Ethiopian Health and Nutrition Research Institute (EHNRI) Review Board, the National Research Ethics Review Committee (NRERC) at the Ministry of Science and Technology, the Institutional Review Board of ICF International, and the communicable disease control (CDC). Additionally, written consent for participation was obtained from each respondent (this was indicated in the EDHS 2016 publications (https://dhsprogram.com/pubs/pdf/FR328/FR328.pdf, page 411)). However; the dataset of the 2016 EDHS is not available as a public domain survey dataset. The author requested access to the data from demographic, health survey program team and access was granted to use the data for this research.

\section{Authors' contributions}

TS: Conceived the study ideas, design, and analyzed data and wrote the draft manuscript; TS and ZK participated in the study design, edited the manuscript and contributed to the final analysis. Both authors read and approved the final manuscript.

\section{Funding}

Not applicable.

\section{Availability of data and materials}

The data sets used and/or analyzed during the current study are available in the Ethiopian statistical agency and ministry of health.

\section{Consent for publication}

Not applicable.

\section{Competing interests}

The authors declare that they have no competing interests.

\section{Author details}

'Department of Epidemiology, Faculty of Public Health, Jimma University, Jimma, Ethiopia. ${ }^{2}$ Biostatistics Unit, Department of Epidemiology, Faculty of Public Health, Jimma University, Jimma, Ethiopia.
Received: 21 September 2019 Accepted: 15 April 2020

Published online: 06 May 2020

\section{References}

1. UNFPA. 2016. Universal Access to Reproductive Health. PROGRESS AND CHALLENGES, 2016. United Nations Population Fund 605 Third Avenue New York, NY 10158 www.unfpa.org.

2. Agyemang J, et al. Contraceptive use and associated factors among sexually active female adolescents in Atwima Kwanwoma District, Ashanti regionGhana. Pan Afr Med J. 2019;32:182. https://doi.org/10.11604/pamj.2019.32. 182.15344.

3. Prata N, Fraser A, Huchko MJ, Gipson JD, Withers M, Lewis S, et al. Womens empowerment and family planninig: a review of the literature. J Biosoc Sci. 2017:1-31. https://doi.org/10.1017/s0021932016000663 PubMed PMID: 28069078; PubMed Central PMCID: PMCEmpowerment. Epub 2017/01/11.

4. United Nations, Department of Economic and Social Affairs, Population Division (2015). Trends in Contraceptive Use Worldwide 2015(ST/ESA/SER.A/ 349).

5. $\mathrm{FMOH}$. (Ethiopia). Costed implementation plan for family planning in Ethiopia, 2015/16-2020. Addis Ababa; 2016.

6. Ochako R, Mbondo M, Aloo S, Kaimenyi S, Thompson R, Temmerman M, Kays M. Barriers to modern contraceptive methods uptake among young women in Kenya: a qualitative study. BMC Public Health. 2015;15:118.

7. Gordon C. Women's Education and Modern Contraceptive Use in Ethiopia. Int J Educ ISSN 1948-5476. 2011;3(1):E9.

8. Kofi J. Modern contraceptive use among women in the Asuogyaman District of Ghana: is reliability more important than health concerns? Afr J Reprod Health La Revue Africaine de la Santé Reproductive. 2013;17(2):5871.

9. Seyife A,Fisseha G,Yebyo H,Gidey G, Gerensea H (2019) Utilization of modern contraceptives and predictors among women in Shimelba refugee camp, northern Ethiopia. PLoS One 14(3):e0212262.dpi: https://doi.org/10. 1371/ journal.pone.

10. Yemaneh Y, Birie B. Assessment of knowledge, attitude and utilization of long acting family planning method among women of reproductive age Groupe in Mizan-Aman Twon, bench-Majizone, south West Ethiopia, 2016. Integr J Glob Health. 2017;1:2.

11. Ditekemena J, Koole O, EngmannC MR, Tshefu A, Ryder R, Colebunders R. Determinants of male involvement in maternal and child health services in sub-Saharan Africa: a review. Reprod Health. 2012;9(1):32.

12. David J. Piller. A. Ethiopia: an emerging family planning success story. Stud Fam Plan. 2013;44(4):445-59.

13. USAID. Trends and Determinants of Contraceptive Use among Young Married Women (Age 15-24) Based on the 2000, 2005, and 2011 Ethiopian Demographic and Health Surveys: A Multivariate Decomposition Analysis. 2014. 103; Rockville.

14. Osuafor GN, Maputle SM, Ayiga N. Factors related to married or cohabiting women's decision to use modern contraceptive methods in Mahikeng, South Africa. Afr J Prm Health Care Med. 2018;10(1):a1431. https://doi.org/ 10.4102/ phcfm.v10i1.1431.

15. Laune F, Alex C. Decision-making patterns and contraceptive use: evidence from Uganda. Popul Res Policy Rev. 2010;29(3):423-39 https://www.jstor org/stable/40608408.

16. Solanke, et al. Maternal grand multiparity and intention to use modern contraceptives in Nigeria. BMC Public Health. 2018:18:1207. https://doi.org/ 10.1186/s12889-018-6130-1.

17. Eshete A, Adissu Y. Women's Joint Decision on Contraceptive Use in Gedeo Zone, Southern Ethiopia: A Community Based Comparative Cross-Sectional Study. Int J Fam Med. 2017, Article ID 9389072,9 pages. https://doi.org/10. 1155/2017/9389072.

18. de Vargas Nunes Coll C, Ewerling F, Hellwig F, et al. Contraception in adolescence: the influence of parity and marital status on contraceptive use in 73 low-and middle-income countries. Reprod Health. 2019;16:21-33.

19. Mussie A, Tefera B, Tizta T: Factors associated with utilization of long acting and permanent contraceptive methods among married women of reproductive age in Mekelle town, Tigray Ethiopia. BMC Pregnancy Childbirth; 2012

20. Eshete A, Adissu Y. Women's Joint Decision on Contraceptive Use in Gedeo Zone, Southern Ethiopia: A Community Based Comparative Cross-Sectional Study. Int J Fam Med. 2017:2017, Article ID 9389072:9. https://doi.org/10. 1155/2017/9389072. 
21. Adelekan A, Omoregie P, Edoni E. Male Involvement in Family Planning: Challenges and Way Forward. Int J Popul Res. 2014;2014(416457):9. https:// doi.org/10.1155/2014/416457.

22. Geleta D, Birhanu Z, Kaufman M, Temesgen B. Gender norms and family planning decision-making among married men and women, rural Ethiopia: a qualitative study. Sci J Public Health. 2015;3(2):242-50 Retrieved from http://www.sciencepublishinggroup.com/journal/paperinfo.aspx?journalid= 251\&doi=10.11648/j.sjph.20150302.23.

23. Kabagenyi A, Jennings L, Reid A, Nalwadda G, Ntozi J, Atuyambe L. Barriers to male involvement in contraceptive uptake and reproductive health services: a qualitative study of men and women's perceptions in two rural districts in Uganda. Reprod Health. 2014;11:21.

24. Kabagenyi A, Ndugga P, Wandera Stephen O, Kwagala B. Modern contraceptive use among sexually active men in Uganda: does discussionwith a health worker matter? BMC Public Health. 2014;14:286.

25. Alemayehu B. Assessment of male involvement in family planning use among men in south eastern zone of Tigray, Ethiopia. Scholarly J Med. 2012;2(2):1-10

26. Kassa M, Abajobir Alemu A, Gedefaw M. Level of male involvement and associated factors in family planning services utilization among married men in Debre Markos town, Northwest Ethiopia. BMC Int Health Hum Rights. 2014;14:33.

27. Central Statistical Agency (CSA) [Ethiopia] and ICF. Ethiopia Demographic and Health Survey 2016. Addis Ababa: CSA and ICF; 2016.

28. USAID/MEASURE EVALUATION. Male Engagement in Family Planning Gaps in Monitoring and Evaluation September 2017; North Carolina, USA.

29. Ochako, et al. Determinants of modern contraceptive use among sexually active men in Kenya. Reprod Health. 2017;14:56. https://doi.org/10.1186/ s12978-017-0316-3.

30. Nsanya MK, Atchison CJ, Bottomley C, et al. Modern contraceptive use among sexually active women aged 15-19 years in North-Western Tanzania: results from the Adolescent 360 (A360) baseline survey. BMJ Open. 2019;9: e030485. https://doi.org/10.1136/ bmjopen-2019-030485.

31. Fagbamigbe AF, et al. Demand and unmet needs of contraception among sexually active in-union women in Nigeria: distribution, associated characteristics, barriers, and program implications. SAGE Open. 2018:1-11. https://doi.org/10.1177/2158244017754023 journals.sagepub.com/home/sgo.

32. Hounton S, et al. Patterns and trends of contraceptive use among sexually active adolescents in Burkina Faso, Ethiopia, and Nigeria: evidence from cross-sectional studies. Glob Health Action. 2015;8:29737. https://doi.org/10. 3402/gha.v8.29737.

33. Oginni AB, Ahonsi BA, Adebajo S. Trend and Determinants of Unmet Need for Family Planning Services among Currently Married Women and Sexually Active Unmarried Women Aged 15-49 in Nigeria (2003-2013). Afr Popul Stud. 2015;29(1) http://aps.journals.ac.za.

\section{Publisher's Note}

Springer Nature remains neutral with regard to jurisdictional claims in published maps and institutional affiliations.

Ready to submit your research? Choose BMC and benefit from:

- fast, convenient online submission

- thorough peer review by experienced researchers in your field

- rapid publication on acceptance

- support for research data, including large and complex data types

- gold Open Access which fosters wider collaboration and increased citations

- maximum visibility for your research: over $100 \mathrm{M}$ website views per year

At BMC, research is always in progress.

Learn more biomedcentral.com/submissions 